\title{
Effects of sample handling and cultivation bias on the specificity of bacterial communities in keratose marine sponges
}

\author{
Cristiane C. P. Hardoim ${ }^{1}$, Massimiliano Cardinale ${ }^{2+}$, Ana C. B. Cúcio ${ }^{1,3}$, Ana I. S. Esteves ${ }^{1+}$, \\ Gabriele Berg ${ }^{2}$, Joana R. Xavier ${ }^{4}$, Cymon J. Cox ${ }^{5}$ and Rodrigo Costa ${ }^{1}$ * \\ ${ }^{1}$ Microbial Ecology and Evolution Research Group, Centre of Marine Sciences, University of Algarve, Faro, Portugal \\ ${ }^{2}$ Institute of Environmental Biotechnology, Graz University of Technology, Graz, Austria \\ ${ }^{3}$ Department of Aquatic Microbiology, Institute for Biodiversity and Ecosystem Dynamics, University of Amsterdam, Amsterdam, Netherlands \\ ${ }^{4}$ Department of Biology, Centre for Geobiology, University of Bergen, Bergen, Norway \\ ${ }^{5}$ Plant Systematics and Bioinformatics, Centre of Marine Sciences, University of Algarve, Faro, Portugal
}

\section{Edited by:}

Torsten Thomas, The University of

New South Wales, Australia

\section{Reviewed by:}

Suhelen Egan, The University of New

South Wales, Australia

Angela Cunha, University of Aveiro,

Portugal

\section{*Correspondence:}

Rodrigo Costa, Microbial Ecology and Evolution Research Group, Centre of Marine Sciences, University of Algarve, Gambelas Campus,

Building 7, Room 2.77, 8005-139 Faro,

Algarve, Portugal

e-mail:rscosta@ualg.pt;

microecoevo@gmail.com

${ }^{\dagger}$ Present address:

Massimiliano Cardinale, Institute of Applied Microbiology,

Justus-Liebig-University, Giessen, Germany;

Ana I. S. Esteves, School of

Biotechnology and Biomolecular

Sciences, Centre for Marine

Bio-Innovation, University of New

South Wales, Sydney, NSW, Australia
Complex and distinct bacterial communities inhabit marine sponges and are believed to be essential to host survival, but our present-day inability to domesticate sponge symbionts in the laboratory hinders our access to the full metabolic breadth of these microbial consortia. We address bacterial cultivation bias in marine sponges using a procedure that enables direct comparison between cultivated and uncultivated symbiont community structures. Bacterial community profiling of the sympatric keratose species Sarcotragus spinosulus and Ircinia variabilis (Dictyoceratida, Irciniidae) was performed by polymerase chain reaction-denaturing gradient gel electrophoresis and 454-pyrosequecing of 16S rRNA gene fragments. Whereas cultivation-independent methods revealed species-specific bacterial community structures in these hosts, cultivation-dependent methods resulted in equivalent community assemblages from both species. Between 15 and 18 bacterial phyla were found in S. spinosulus and I. variabilis using cultivation-independent methods. However, Alphaproteobacteria and Gammaproteobacteria dominated the cultivation-dependent bacterial community. While cultivation-independent methods revealed about 200 and 220 operational taxonomic units (OTUs, $97 \%$ gene similarity) in S. spinosulus and I. variabilis, respectively, only 33 and 39 OTUs were found in these species via culturing. Nevertheless, around $50 \%$ of all cultured OTUs escaped detection by cultivation-independent methods, indicating that standard cultivation makes otherwise host-specific bacterial communities similar by selectively enriching for rarer and generalist symbionts. This study sheds new light on the diversity spectrum encompassed by cultivated and uncultivated sponge-associated bacteria. Moreover, it highlights the need to develop alternative culturing technologies to capture the dominant sponge symbiont fraction that currently remains recalcitrant to laboratory manipulation.

Keywords: holobiont, microbial cultivation, microbial diversity, pyrosequencing, symbiosis

\section{INTRODUCTION}

"The great plate count anomaly," as introduced by Staley and Konopka (1985), describes the difference observed between the number of bacterial colony forming units (CFUs) grown on a culture medium and that of cells detected by microscopy for a given sample. This way, it was estimated that only $0.1-1.0 \%$ of the total bacterial cells in the environment could be accessed via standard cultivation approaches (Staley and Konopka, 1985). This result was supported by several studies of free-living (Kogure et al., 1979; Staley and Konopka, 1985; Amann et al., 1995) and hostassociated bacterial communities (Friedrich et al., 2001; Webster and Hill, 2001). However, the plate count anomaly as originally described disregards the phylogenetic diversity of those CFUs grown on plates and uncultivated cells observed under the microscope (Donachie et al., 2007): the ratio CFU/microscopy cell counts, when directly used to describe "cultivation bias," assumes even relative abundances between all microbial species or phylotypes that constitute the community. Despite this assumption, natural communities more often display uneven species abundances in which a few members dominate the assemblage followed by a majority of diverse, but rarer, species or phylotypes (Sogin etal., 2006; Gomes et al., 2010; Webster et al., 2010; Hardoim et al., 2013). Unfortunately, microbial ecologists have tended to overlook this pattern in the past when referring to our capacity to cultivate microbial species from the environment (Donachie et al., 2007). Several questions remain poorly understood, for instance, how does the diversity of readily cultivatable microorganisms compare with that resulting from cultivation-independent methods? Are we culturing the few dominant members of a community or preferentially the rare ones? Do communities resulting from cultivation-dependent and cultivation-independent methods share a majority of microbial 
phylotypes or are these communities divergent? Few studies have addressed these questions in detail (Donachie et al., 2007; Li et al., 2011; Sipkema et al., 2011; Montalvo et al., 2014), a situation which severely restricts our knowledge of the extent of the cultivatable microbiome diversity from natural habitats.

Marine sponges are reservoirs of microbial genetic and metabolic novelties. Up to 28 bacterial phyla, including candidate phyla, have been found in association with these animals (Simister et al., 2012). This conspicuous taxonomic diversification suggests functional variety, and several possible roles have been proposed for sponge symbionts upon interaction with their hosts (Taylor et al., 2007b; Webster and Taylor, 2012). Among them, the putative chemical defense enabled by biologically active compounds produced by sponge-associated bacteria is receiving considerable attention (Piel et al., 2004; Hochmuth and Piel, 2009; Siegl and Hentschel, 2010; Thomas et al., 2010b; Hentschel et al., 2012). Consequently, cultivating marine sponge bacteria is important from both a phylogenetic and biotechnological standpoint. Several attempts have been made to domesticate sponge-associated bacteria (Muscholl-Silberhorn et al., 2008; Esteves et al., 2013). Nevertheless, few studies assessed cultivationdependent and -independent discrepancies in diversity surveys of the sponge microbiome (Sipkema et al., 2011; Montalvo et al., 2014).

The present study uses polymerase chain reaction-denaturing gradient gel electrophoresis (PCR-DGGE) and 454-pyrosequencing profiling to address the extent to which culturing and specific sample handling procedures affect the structure of bacterial communities in the keratose marine sponges (i.e., lacking mineral spicules and possessing an organic fibers skeleton instead) Sarcotragus spinosulus Schmidt 1862 and Ircinia variabilis Schmidt 1862. Previous studies suggest that these species harbor divergent bacterial communities and are the source of cultivatable bacteria with antimicrobial capacities (Hardoim et al., 2012; Esteves et al., 2013). However, the full diversity breadth of these microbial consortia and of their corresponding cultivatable fraction remains to be determined. We employed a strategy that circumvents the need to isolate single colonies during diversity surveys of cultivated bacteria and instead enables the direct comparison between bacterial community structures retrieved with cultivation-dependent and cultivation-independent methods. Although fewer bacterial species are usually recovered by cultivation than by cultivation-independent approaches, we hypothesized that cultivation would nevertheless represent the phylogenetic diversity of the communities assessed here to a higher extent than expected from CFU/microscopy count ratios. We also applied in-tube fluorescent in situ hybridization (FISH) of dominant sponge-associated bacteria to obtain the first insights into their localization and distribution in the two sponge species, and to compare the relative abundances of the bacterial symbionts estimated using sequencing and cell imaging technologies.

\section{MATERIALS AND METHODS SPONGE AND SEAWATER SAMPLING}

Sampling took place at Galé Alta, Armação de Pêra (37 04'09.6”N and $8^{\circ} 19^{\prime} 52.1^{\prime \prime} \mathrm{W}$ ) off the coast of the Algarve, southern Portugal, in June 2010. Four specimens of S. spinosulus and I. variabilis (Demospongiae, Dictyoceratida, Irciniidae), and four samples of surrounding seawater $(1 \mathrm{~L}$ each, about $1 \mathrm{~m}$ above sponge specimens), were collected in sterile Ziploc ${ }^{\circledR}$ bags by scuba diving at about $15 \mathrm{~m}$ depth. Samples were placed in cooling boxes, transported to the laboratory (c. $2 \mathrm{~h}$ ) and immediately processed as described below. Sponge species were identified based on macroand microscopic morphological criteria coupled to molecular phylogenetic inference (Hardoim et al., 2012).

\section{CULTIVATION-INDEPENDENT AND -DEPENDENT TOTAL COMMUNITY DNA EXTRACTION}

For each collected sponge specimen, three procedures of sample processing were undertaken prior to total community DNA (TC-DNA) extraction, hereafter called "direct," "indirect," and "plate washing" methods of sponge sample processing. The first two methods lead to cultivation-independent analysis of TC-DNA directly extracted from the sponge body ("direct" method) or from sponge-derived microbial cell pellets ("indirect" method). "Plate washing" involves extracting TC-DNA from washes of Marine Agar culture plates and is therefore a culture-dependent methodology for assessing the sponge-associated microbiome without having to purify and singularize colonies. Details of each procedure are given in Appendix S1 (Supplementary Material). TC-DNA extraction was performed with the UltraClean ${ }^{\circledR}$ Soil DNA isolation kit (MO BIO, Carlsbad, CA, USA), according to the manufacturer's protocol. The same kit was used for TC-DNA extraction from bulk seawater samples following Hardoim et al. (2012). Thus, 28 metagenome samples (four seawater replicates; four I. variabilis replicates handled with "direct," "indirect," and "plate washing" methods; and four S. spinosulus replicates handled with "direct," "indirect," and "plate washing" methods) were subjected to PCRDGGE and 454-pyrosequencing bacterial community profiling as explained below.

\section{PCR-DGGE BACTERIAL COMMUNITY PROFILING}

A nested PCR-DGGE approach targeting the V6 hypervariable region of the $16 \mathrm{~S}$ rRNA gene was used to fingerprint the bacterial communities associated with both sponge species under the three methods of sample processing. The reaction mixture and thermal cycling for both reactions were as described by Hardoim etal. (2012), except for the concentration of primers $(0.6 \mu \mathrm{M}$, Table 1). PCR-DGGE profiling was then performed using a PhorU-2 gradient system (Ingeny International, Goes, The Netherlands). Gel gradient, marker constituents, electrophoresis and staining procedures were described previously (Hardoim et al., 2012). Multivariate statistical analysis of PCR-DGGE fingerprints followed methods described elsewhere (Costa etal., 2006; Hardoim etal., 2009) and is detailed in Appendix S1.

\section{4-PYROSEQUENCING BACTERIAL COMMUNITY PROFILING}

A barcoded pyrosequencing approach was employed for in-depth analysis of bacterial community composition and diversity. A thorough description of (i) pyrosequencing sample preparation, (ii) data processing and (iii) analyses is provided in Appendix $\mathrm{S} 1$. Briefly, the V4 hypervariable region of the $16 \mathrm{~S}$ rRNA gene 
Table 1 | Polymerase chain reaction-denaturing gradient gel electrophoresis and 454-pyrosequencing primers used in this study.

\begin{tabular}{llll}
\hline Name & Sequence $\left(\mathbf{5}^{\prime} \mathbf{-} \mathbf{3}^{\prime} \mathbf{)}\right.$ & Usage & Reference \\
\hline F27 & AGAGTTTGATCMTGGCTCAG & First DGGE PCR & Weisburg et al. (1991) \\
R1492 & TACGGYTACCTTGTTACGACTT & First DGGE PCR & Weisburg etal. (1991) \\
F984-GC & CGCCCGGGGCGCCCCCGGGCGGGG & Second DGGE PCR & Heuer et al. (1997) \\
& CGGGGGCACGGGGGGACGCGAAGACCTTAC & & \\
R1378 & CGGTGTGTACAAGGCCCGGGAACG & Second DGGE PCR & Heuer et al. (1997) \\
V4_titF & AYTGGGYTAAAGNG & 454-Pyrosequencing & http://pyro.cme.msu.edu/pyro/help.jsp\#intro \\
V4_tit_R & TACNVRRGTHTCTAATYC & 454-Pyrosequencing & http://pyro.cme.msu.edu/pyro/help.jsp\#intro \\
\hline
\end{tabular}

was PCR-amplified using the Ribosomal Database Project primer set (Table 1), which generates amplicons of around $248 \mathrm{bp}$ in length. Two PCR mixtures of $25 \mu \mathrm{L}$ were prepared per sample, each containing $\sim 20$ ng of template DNA. Each sample was tagged by unique 8 -mer barcodes attached to the reverse primer. The amplicons were delivered for pyrosequencing on a 454 Genome Sequencer GS FLX Titanium platform (Roche Diagnostics Ltd, West Sussex, UK) at BIOCANT (Biotechnology Innovation Center, Cantanhede, Portugal). Raw data were processed using AmpliconNoise (Quince et al., 2011) and Galaxy (https://main.g2.bx.psu.edu/; Taylor et al., 2007a), enabling noise filtering (e.g., homopolymers), chimera removal, sequence sorting, and trimming. The Quantitative Insights Into Microbial Ecology (QIIME) software package (Caporaso et al., 2010) was then applied to the filtered data set for operational taxonomic units (OTUs) determination and taxonomic assignment, followed by the generation of a samples-OTUs table using customized scripts (Appendix S1). Data analyses encompassed (i) phylum- and classlevel bacterial composition in individual and pooled samples, (ii) assessment of specific and shared bacterial symbionts across sample groups via OTU networks and Venn diagrams, (iii) estimates of symbiont richness (Chaol) and diversity (Shannon's index) and (iv) multivariate analysis of OTU data. The latter was performed via (a) principal coordinate analysis (PCoA) of OTU profiles using the Unifrac metric within QIIME and (b) constrained ordination of OTU profiles and independent variables (i.e., seawater, sponge, sponge species, and sample processing methods) with the software package Canoco for Windows 4.5 using Hellinger-transformed OTU abundance data. Analyses (i) to (iv) were carried out using both full size (whole data set exploration) and size-normalized sample libraries. The analysis of full size libraries was used to determine the absolute number (and the identity) of all OTUs shared by and specific to each sample category $(n=7$ : seawater; I. variabilis under "direct," "indirect," and "plate washing" methods; and S. spinosulus under "direct," "indirect," and "plate washing" methods). The analysis of normalized libraries was applied in the quantitative comparison of bacterial richness, diversity and community structure between the sample categories. For sizenormalized analyses, two depth thresholds were defined, 1236 and 3688 sequence reads per sample, which allowed the comparison of (i) all four replicate samples of both sponge species under the three methods of sample processing and triplicate seawater samples, and (ii) all sponge-derived libraries (seawater samples excluded), respectively. Similar analyses were performed for the unfiltered data set, disregarding chimera and noise removal procedures. Pyrosequencing data were deposited in the National Center for Biotechnology Information (NCBI) Sequence Read Archive (SRA) under the accession number SRP021445.

\section{IN-TUBE FLUORESCENT IN SITU HYBRIDIZATION AND CONFOCAL LASER SCANNING MICROSCOPY (FISH-CLSM)}

To determine the spatial distribution and infer the abundance of sponge-associated bacteria at the micro-scale, in-tube FISHCLSM was performed as described by Cardinale et al. (2008) with slight modifications (Appendix S1). For the detection of all bacteria, an equimolar mixture of Cy3-labeled EUB338, EUB338II, and EUB338III probes was used (Amann et al., 1990, Table 2). Samples were further hybridized with ALEXA488- or Cy5-labeled FISH probes specific for Acidobacteria (SS_HOl1400; Meisinger et al., 2007), Alphaproteobacteria (ALF968; Neef, 1997), and Gammaproteobacteria (Gam42a; Manz et al., 1992; Table 2). These taxa were selected based on their predominance revealed by 454-pyrosequencing. Taxon-specific abundances relative to total bacterial cell density were calculated by averaging the fraction of specifically stained cells from at least 15 randomly selected fields (confocal stacks) retrieved from three independent FISH experiments per specific probe.

\section{TESTS OF SIGNIFICANCE}

Homogeneity of variance tests were used to inspect the normal distribution of the richness and diversity measurements from PCR-DGGE fingerprints and 454-pyrosequencing. Analysis of variance (ANOVA) tested whether the mean values obtained for all sample groups ( $n=7$ : seawater; I. variabilis under "direct," "indirect," and "plate washing" methods; and S. spinosulus under "direct," "indirect," and "plate washing" methods) were equal. A pairwise $t$-test which analyses the significance between groups was then carried out. Homogeneity of variance and ANOVA were also employed to compare 454-pyrosequencing relative abundances of the most dominant bacterial phyla and classes found across groups. The analyses were performed with the stat package in R programming ( $\mathrm{R}$ Development Core Team, 2012). For both PCR-DGGE and 454-pyrosequencing data, Monte-Carlo permutations were performed to test whether the generated 
Table 2 | Fluorescent in situ hybridization probes used in this study.

\begin{tabular}{|c|c|c|c|c|}
\hline Name & Sequence $\left(5^{\prime}-3^{\prime}\right)$ & Target & Formamide $(\%)^{1}$ & Reference \\
\hline EUB338² & gctgcctcccgtaggagt & Most bacteria & 20 & Amann etal. (1990) \\
\hline EUB338॥ ${ }^{2}$ & gcagccacccgtaggtgt & Planctomycetales & 20 & Daims et al. (1999) \\
\hline EUB338III2 & gctgccacccgtaggtgt & Verrucomicrobiales & 20 & Daims etal. (1999) \\
\hline ALF968 & ggtaaggttctgcgcgtt & Alphaproteobacteria & 40 & Neef (1997) \\
\hline Gam42a & gccttcccacatcgttt & Gammaproteobacteria & 40 & Manz et al. (1992) \\
\hline SS_HOL1400 & ttcgtgatgtgacgggc & Acidobacteria & 20 & Meisinger et al. (2007) \\
\hline NONEUB & actcctacgggaggcagc & - & 3 & Wallner et al. (1993) \\
\hline
\end{tabular}

${ }^{1}$ Concentration of formamide for hybridizations at $43^{\circ} \mathrm{C}$.

2 Used in a mixture of equimolar concentrations.

3 Used as negative control with the same formamide concentration as used for positive FISH.

sponge symbiont profiles clustered according to the sample groups.

\section{RESULTS}

PCR-DGGE FINGERPRINTING OF BACTERIAL COMMUNITIES

The PCR-DGGE profiles of $S$. spinosulus obtained with cultivation-independent "direct" and "indirect" sample processing methods were visually very similar whereas much larger band variation was observed between I. variabilis fingerprints generated using the same methods (Figure 1). Profiles obtained for both sponge species via "plate washing" were different from those generated by cultivation-independent methods (Figure 1A). Ordination analysis of PCR-DGGE banding patterns suggested that both the host species and processing methods determined the structures of the surveyed symbiont communities (Figure 1B). A detailed description of PCR-DGGE results and a discussion on how they compare with 454-pyrosequencing data are given as Supplementary Material (Table S1, Appendix S2).

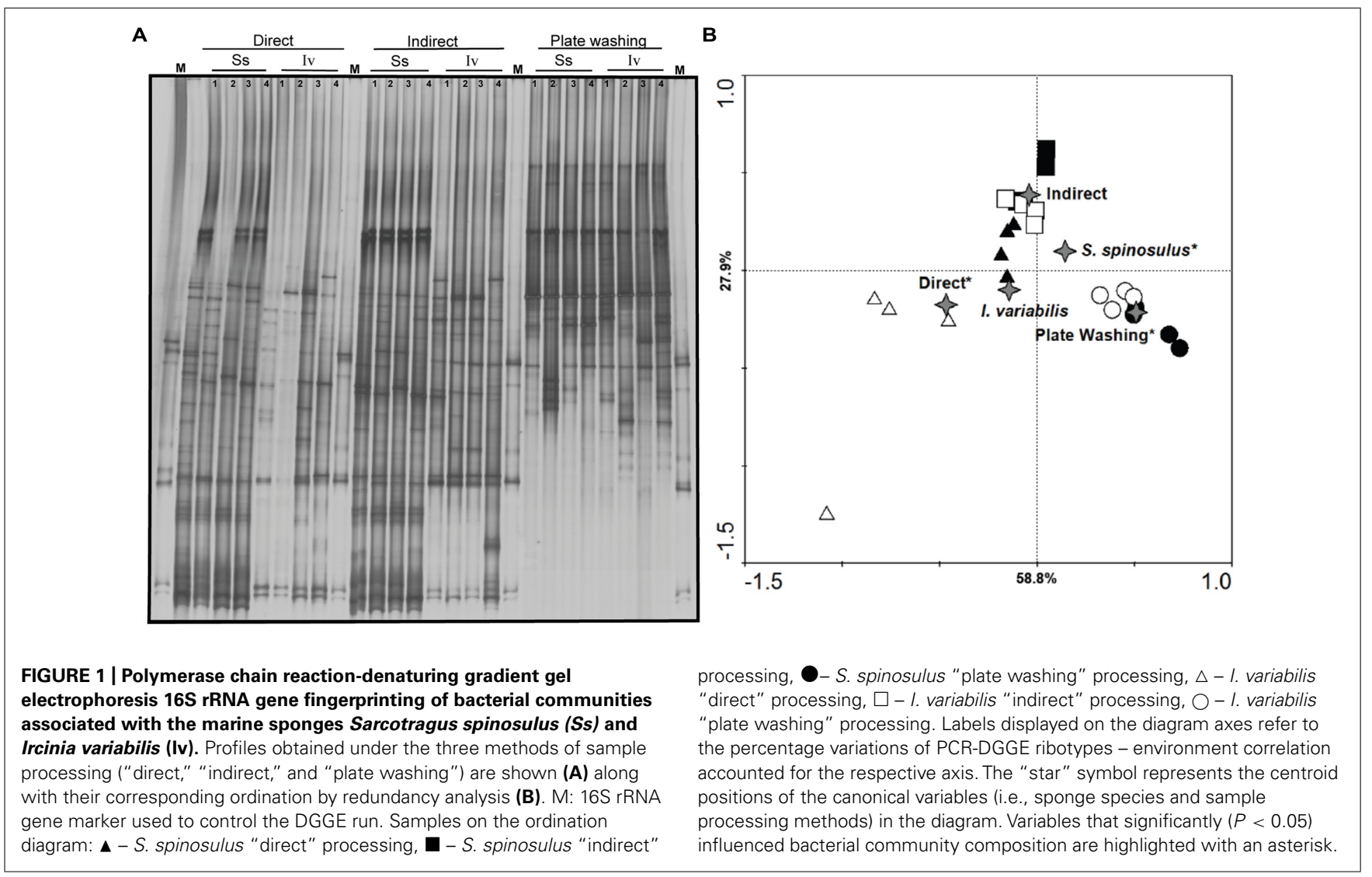




\section{4-PYROSEQUENCING}

\section{Bacterial richness and diversity}

A total of 237,773 16S rRNA V4-tag sequences passed preliminary filtering on the 454 apparatus. After sequence trimming and further quality filtering, 166,442 bacterial 16S rRNA gene V4tag sequences were obtained and constituted the analytical data set. Sequences were assigned to 639 OTUs at a 97\% similarity cut-off (Table 3). Considering all normalized sequence libraries (depth $=1236$ sequences/sample), about twofold higher bacterial richness was observed in seawater than in sponge samples (Figures 2A,E). Bacterial richness increased significantly in both sponge species - and across all processing methods - when analyses were made with larger libraries (depth $=3668$ sequences/sample). In this case, S. spinosulus and I. variabilis hosted from $c .80$ to 95 bacterial OTUs/specimen under cultivation-independent methods (Figures 2B,E). Regardless of the sequence depth, two major trends were found across the data. First, a large reduction in bacterial symbiont richness and diversity was observed for both sponge species because of culturing (Figures 2A-E). Specifically, the number of bacterial OTUs detected using the "plate washing" method represented only 11.9 and $15.25 \%$ of the OTU richness recorded for S. spinosulus and I. variabilis, respectively, when using the "direct" method. Second, when cultivation-independent methods were compared, contrasting results were obtained for each sponge host. Whereas no difference in richness and diversity values was found for S. spinosulus treated with both the "direct" and "indirect" methods, handling of $I$. variabilis with the "indirect" method resulted in significant reduction of such estimates in this host (Figures 2A-E). Overall, Shannon diversity indices were not affected by the size of libraries used in the comparisons (Figures 2C,D), and seawater and S. spinosulus bacterial diversities obtained with culture-independent methods were of comparable magnitude (Figure 2C) in spite of the significantly higher bacterial richness detected in seawater (Figure 2A). Our sequencing effort (see Table 3 for details) was found to encompass about 65,81 , and $84 \%$ of the estimated bacterial diversity in seawater, S. spinosulus and I. variabilis samples ("direct" method), respectively, while the diversity found in the cultivatable bacterial fraction was fully covered. Richness and diversity estimates for the unfiltered sequencing data are given in Figure S1 (Supplementary Material).

\section{Community composition at the phylum level}

All major bacterial phyla detected in this study displayed significant shifts in relative abundance either as a function of the surveyed microenvironment (seawater $v$ s. sponge), the host species (S. spinosulus vs. I. variabilis) or the sample processing method ("direct" vs. "indirect" vs. "plate washing"). Trends observed for the full quality-filtered data set (Figure 3), described below, were consistently reproduced when analyses made with size-normalized libraries were performed (Appendix S3, Supplementary Material). Seawater presented much lower bacterial richness at the phylum level than sponges (Figure 3A), it being largely dominated by Bacteroidetes (90 OTUs in 4918 sequences) and Proteobacteria (156 OTUs in 3401 sequences), which accounted for 57 and $40 \%$ of all sequences, respectively (Figure 3A, Table 4). By contrast, up to 21 bacterial phyla (438 OTUs in 157,786 sequences across all methods) could be detected in the sponge samples (Figure 3A), with each individual specimen usually hosting between 14 and 16 phyla (Figure S2, Supplementary Material). Cultivation-dependent bacterial communities from both sponges consisted mainly of Proteobacteria (>97\% of all sequence reads) and were much reduced in phylum diversity when compared to cultivation-independent communities (Figure 3A). The most abundant sponge-associated phyla found using cultivation-independent methods were Proteobacteria, Actinobacteria and Acidobacteria (Figure 3A, Figure S2A). Considering only these methods, Proteobacteria was the most diverse phylum in sponges (188 OTUs in 16,127 sequences) followed by Actinobacteria (29 OTUs in 26,931 sequences) and Acidobacteria (27 OTUs in 30,346 sequences; Table 4). Differences in phylum relative abundances, without changes to within-phylum OTU richness, were observed among $I$. variabilis communities depending on which cultivation-independent method was used. For instance, higher abundance of Acidobacteria at the expense of much lower proportions of Proteobacteria and Bacteroidetes were retrieved with the "indirect" method when compared to the

Table 3 | Sequence data summary.

\begin{tabular}{|c|c|c|c|c|c|c|}
\hline \multirow[t]{2}{*}{ Sample type } & \multirow[t]{2}{*}{ Sample processing } & \multirow[t]{2}{*}{$\mathbf{N}$} & \multicolumn{2}{|c|}{454 filtering } & \multicolumn{2}{|c|}{ 454+AmpliconNoise filtering } \\
\hline & & & Sequences & OTUs 97 & Sequences & OTUs 97 \\
\hline & Indirect & 4 & 34,988 & 705 & 29,227 & 184 \\
\hline & Plate washing & 4 & 27,497 & 247 & 24,547 & 33 \\
\hline & Indirect & 4 & 25,899 & 541 & 22,686 & 225 \\
\hline & Plate washing & 4 & 31,983 & 257 & 27,930 & 39 \\
\hline Seawater & n.a. & 4 & 15,567 & 598 & 8656 & 329 \\
\hline Total & n.a. & 28 & 200,635 & 1974 & 166,442 & 639 \\
\hline
\end{tabular}

$N$, number of replicate samples; n.a., not applicable. 



E

\begin{tabular}{ccc}
\hline Samples & $\begin{array}{c}\text { Observed Richness } \pm \text { SD } \\
(\mathbf{n}=1236 \text { sequences })\end{array}$ & $\begin{array}{c}\text { Observed Richness } \pm \text { SD } \\
(\mathbf{n}=\mathbf{3 6 8 8} \text { sequences })\end{array}$ \\
\hline Ss_D & $73.82 \pm 4.93$ & $95.80 \pm 5.75$ \\
Ss_I & $66.95 \pm 7.03$ & $89.85 \pm 9.55$ \\
Ss_PW & $7.57 \pm 2.20$ & $11.37 \pm 2.53$ \\
Iv_D & $65.32 \pm 8.23$ & $91.80 \pm 8.00$ \\
Iv_I & $43.25 \pm 8.54$ & $77.17 \pm 15.90$ \\
Iv_PW & $10.1 \pm 4.90$ & $14.00 \pm 5.62$ \\
SW & $129.5 \pm 23.0$ & - \\
\hline
\end{tabular}

FIGURE 2 | Quantitative analysis of bacterial richness and diversity in marine sponges and seawater. Observed and estimated (Chao1) richness measures (A,B), Shannon diversity indices (C,D) and observed richness \pm standard deviation (E) of bacterial OTUs are displayed using normalized depths of 1236 [includes seawater libraries, $(\mathbf{A}, \mathbf{C}, \mathbf{E})$ ] and 3866 [sponge libraries only, (B,D,E)] sequences per library. OTUs were determined at $97 \% 16 \mathrm{~S}$ rRNA gene similarity. Values on bars are mean \pm standard deviation of four replicates within each sample category, except for seawater where three replicates were used. Bars labeled with different letters represent statistically distinct sample categories in terms of richness and/or diversity values. In (A,B), uppercase letters define differences in estimated richness across sample categories, whereas lowercase letters define differences in observed richness. Ss_D, Sarcotragus spinosulus under the "direct" processing method; Ss_I, S. spinosulus under the "indirect" processing method; Ss_PW, S. spinosulus under the "plate washing" processing method; IV_D, I. variabilis under the "direct" processing method; IV_I, I. variabilis under the "indirect" processing method; Iv_PW, I. variabilis under the "plate washing" processing method; SW, seawater. "direct" method (Figure 3A, Figure S2A, Table 4). In contrast, differences in relative abundances of phyla because of cultivationindependent, sample handling methods were negligible in $S$. spinosulus (Table 4).

Taxonomic classes within the most abundant phyla were assigned to OTUs when possible (Figure 3B). In seawater, Flavobacteriia (Bacteroidetes, 67 OTUs in 4576 sequences), Alphaproteobacteria (64 OTUs in 1803 sequences) and Gammaproteobacteria (62 OTUs in 1511 sequences) were the dominant classes (Figure 3B, Figure S2B). Comprising 113 OTUs in 14,270 sequences and 72 OTUs in 50,256 sequences across all processing methods, Gammaproteobacteria and Alphaproteobacteria, respectively, were the most abundant classes in the culture-dependent sponge bacterial communities. Using cultivation-independent procedures, however, their dominance was shared with several other classes, namely Sphingobacteriia (Bacteroidetes, 23 OTUs in 6478 sequences), Acidimicrobiia (Actinobacteria, 21 OTUs in 26,820 sequences), Deltaproteobacteria (20 OTUs in 2788 sequences), Anaerolinea (Chloroflexi, 14 OTUs in 2994 sequences) and Sva075 (Acidobacteria, 8 OTUs in 26,599 sequences; Figure 3B, Figure S2B). 
A

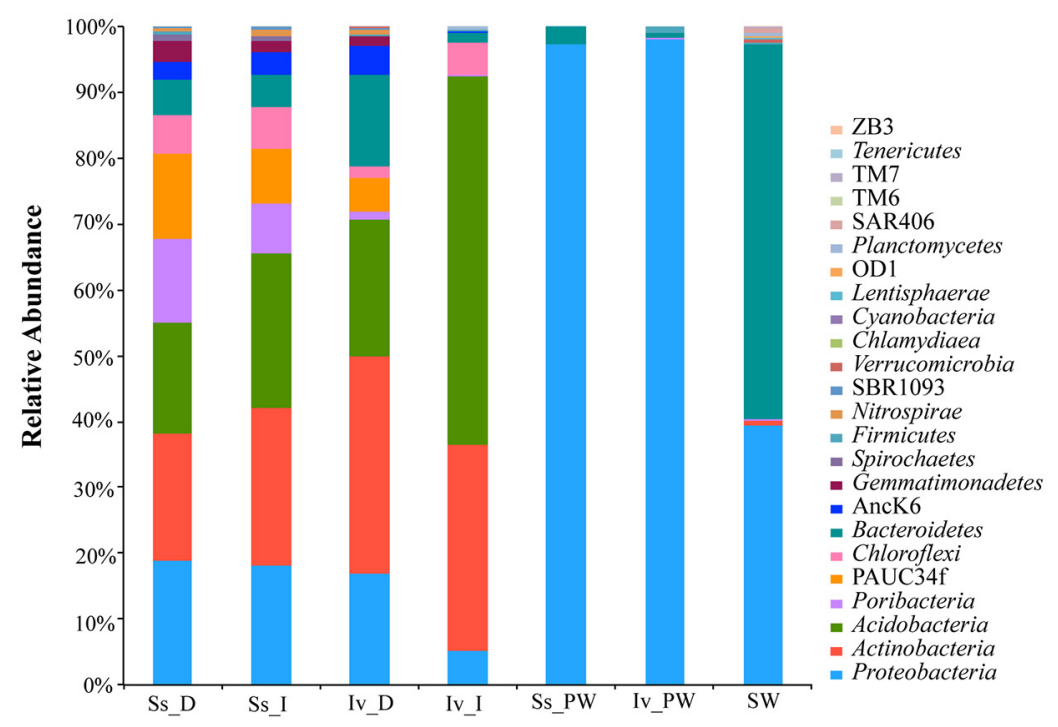

B



FIGURE 3 | Phylum- (A) and class-level (B) bacterial community composition in marine sponges and seawater. Compositional data for S. spinosulus and I. variabilis handled with the "direct," "indirect," and "plate washing" processing methods are shown. Results obtained using pooled replicate samples $(n=4)$ within each sample category are displayed. Bacterial community composition in each replicate sample is shown as Supplementary Material (Figure S2). In (B) the top 18 bacterial classes are listed and all remaining taxa are labeled as "others." Labeling of sample categories is as described in legend to Figure 2.

\section{Specificities and commonalities: shared and exclusive OTUs}

Operational taxonomic units network analysis revealed that most bacterial OTUs found in seawater were specific to this environment, placing the bacterioplankton far apart from symbiotic communities (Figure 4A). Several bacterial OTUs exclusive to the "direct" and "indirect" methods were detected in I. variabilis community profiles, positioning $I$. variabilis samples processed with these methods farther apart from one another than the corresponding S. spinosulus samples in the network diagram (Figure 4A). Cultivation-dependent methods resulted in similar community compositions in both sponges, with only a few
OTUs specific to each sponge species (Figure 4A). These trends were quantified using Venn diagrams (Figures 4B-G). Strikingly, only 4 and 13 bacterial OTUs were common to all three methods of sample processing in S. spinosulus and I. variabilis, respectively (Figures 4B,C). The proportion of OTUs specific to either of the cultivation-independent ("direct" and "indirect") methods was indeed higher in I. variabilis than in S. spinosulus (Figures 4B,C). Despite the reduced bacterial diversity retrieved from the cultivation-dependent "plate washing" method, this approach led to the detection of several "cultivation-specific" OTUs not observed using cultivation-independent methods 
Table 4 | Number of OTUs and sequences per bacterial phylum across sample categories.

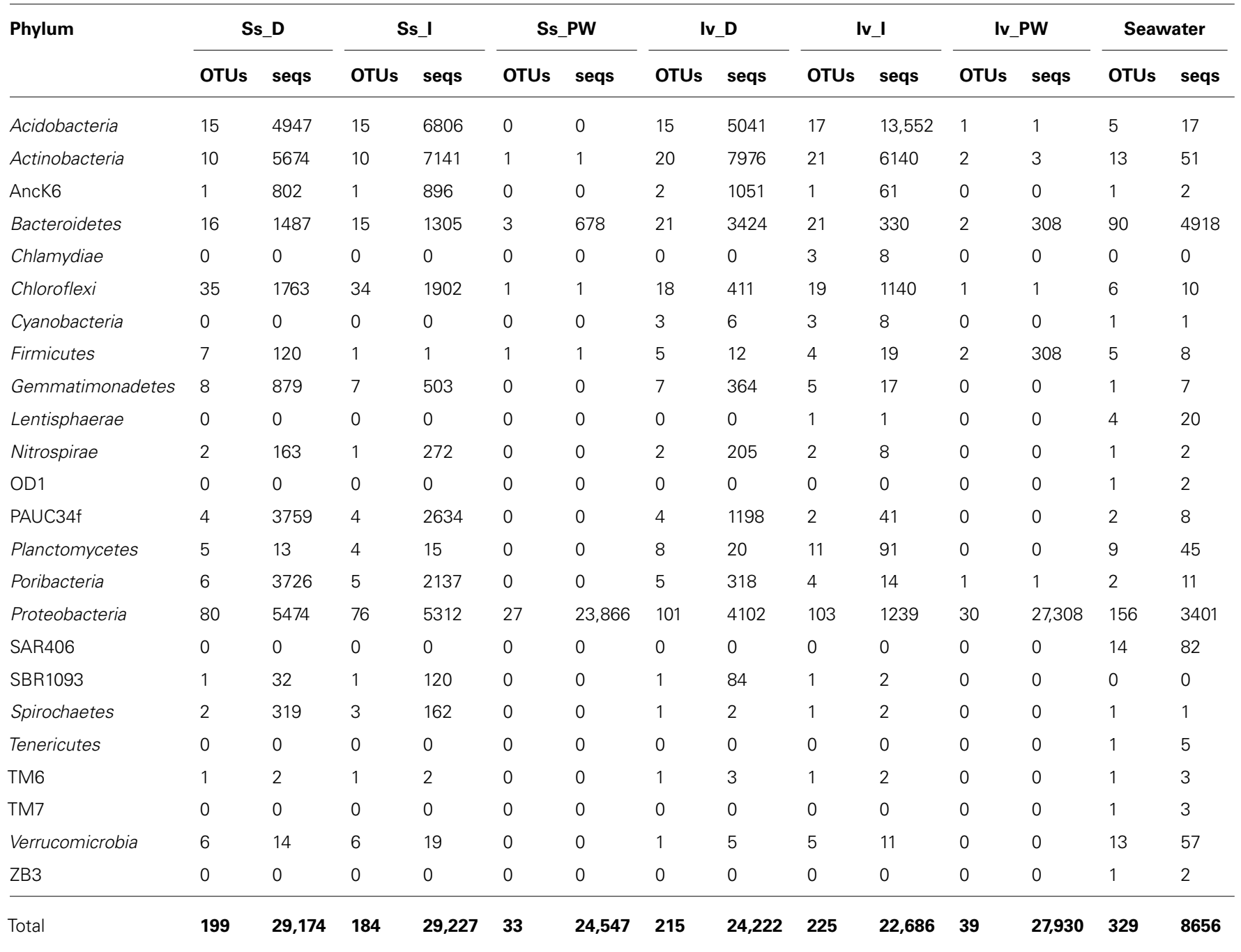

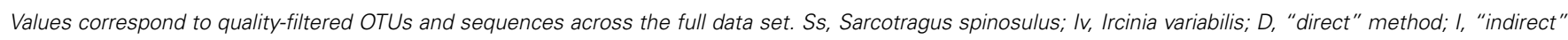
method; PW, "plate washing" method; seqs, sequence.

(Figures 4B,C). Dominant OTUs in the cultivatable community included the genera Pseudovibrio, Vibrio, Shewanella, Aquimarina, Ruegeria, and Microbulbifer. However, none of these taxa were ranked among the dominant OTUs captured by cultivationindependent methods. Unexpectedly, Poribacteria, Chloroflexi (SAR 202) and Acidobacteria (Sva0725) lineages were found in the cultivatable sponge community, however, each taxon was represented by one single OTU consisting of only one sequence read.

Irrespective of sample processing methods, 167 bacterial OTUs were found common to S. spinosulus and I. variabilis, while 103 and 168 bacterial OTUs were exclusively associated with each species, respectively (Figure 4D). For each sponge species, the most abundant "species-specific" OTU was affiliated with the Bacteroidetes phylum (class Sphingobacteriia). Bacterial OTUs found common to seawater and sponge communities from all processing methods numbered just 4 OTUs shared between $S$. spinosulus and seawater and five OTUs shared between $I$. variabilis and seawater (Figures $\mathbf{4 E}, \mathbf{F}$ ). These numbers rose to 32 bacterial OTUs shared by both sponge species with seawater when only cultivation-independent methods were considered (Figure 4G).

Analyses performed only with OTUs containing at least 50 sequences (i.e., "rare" symbionts discarded) showed that the number of otherwise considered "species-specific" or "methodspecific" OTUs dramatically decreased (Figure S3, Supplementary Material). Notably, the community of "rare" OTUs was highly diverse in both sponge species, encompassing 163 and 236 OTUs found in S. spinosulus and I. variabilis, respectively, of which 86 and 160 OTUs were exclusive to each sponge species (Table S2, Supplementary Material). These OTUs comprised typical sponge-associated phyla encountered in the dominant symbiont pool such as Acidobacteria, Actinobacteria, Chloroflexi, Proteobacteria (Alpha and Gamma classes) and Poribacteria (Tables S2A,B). A thorough overview of the taxonomic affiliation of OTUs shared by or specific to the host species and processing 
A



E

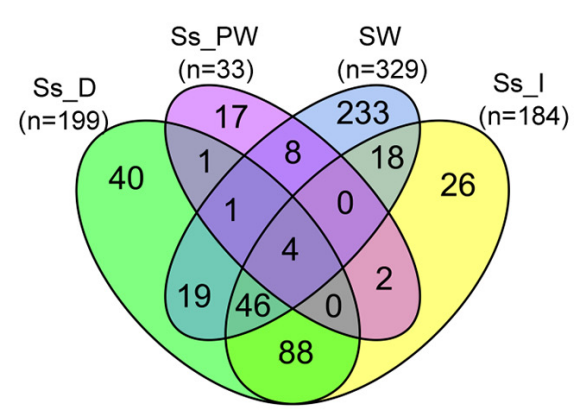

B

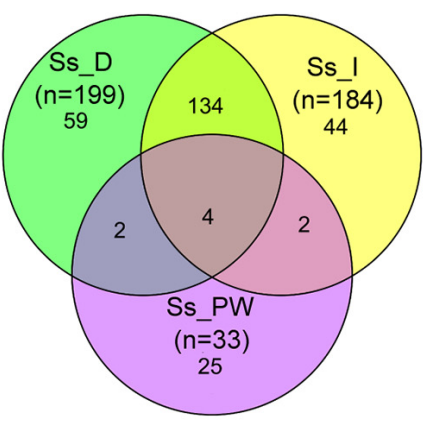

C

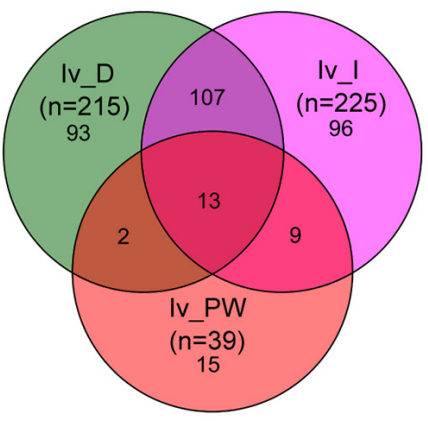

D

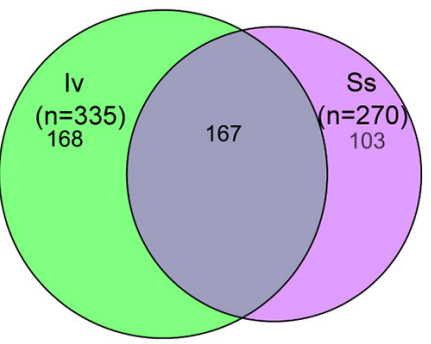

G

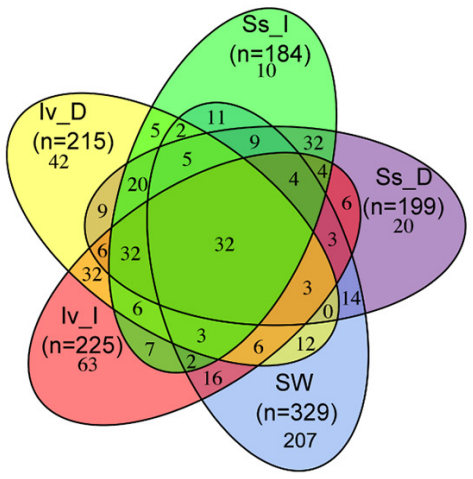

FIGURE 4 | Bacterial OTU networking and Venn diagrams. All OTUs detected across all samples are included in the analysis. In the network diagram (A), gradients of green correspond to $S$. spinosulus samples (light green: "plate washing" processing, green: "indirect" processing, dark green: "direct" processing), and gradients of pink to I. variabilis samples llight pink: "plate washing" processing, pink: "indirect" processing, dark pink: "direct" processing) along with their corresponding OTUs. Seawater samples and their corresponding OTUs are shown in blue. Venn diagrams (B,C) enumerate OTUs from S. spinosulus and I. variabilis, respectively, shared by and exclusive to the different methods of sample processing.
Diagram (D) shows all OTUs detected in, shared by and exclusive to $S$. spinosulus and I. variabilis by merging the data obtained with the three processing methods. Diagrams (E,F) depict the degree of exclusiveness and sharedness between each species (under each of the three processing methods) and seawater, whereas diagram (G) compares marine sponge and seawater bacteriomes as determined by cultivation-independent methods only (i.e., "plate washing" sponge processing excluded). Labeling of sample categories is as described in legend to Figure 2. An equivalent analysis including only OTUs containing $\geq 50$ sequences is shown as Supplementary Material (Figure S3). 
methods surveyed in this study is provided in Appendix S4 (Supplementary Material). Highly congruent results with those reported above were obtained when network analysis was applied to size-normalized data sets (Appendix S5, Supplementary Material).

\section{Ordination of bacterial OTUs}

For the first sequence threshold comparison (1236 sequences/ sample), two concise sample clusters could be visualized by PCoA: (i) all seawater replicates, and (ii) all sponge specimens processed with the "plate washing" method (Figure 5A). The remaining samples comprised all sponge replicates processed via cultivation-independent methods. The PCoA analyses showed a high similarity within $S$. spinosulus replicates treated with both cultivation-independent methods, while there was a lower correspondence between methods and higher individual-to-individual variability detected for I. variabilis samples (Figure 5A). After increasing the sequence depth by removing the seawater samples from the analysis (3688 sequences/sample, Figure 5B), the sharp dichotomy between sponge samples handled with cultivation-dependent and cultivation-independent methods persisted, whereas the divergence between $I$. variabilis specimens treated with cultivation-independent procedures became more apparent. For both sequence thresholds, the 3D plots were helpful in demonstrating correspondences between the samples and some of the most abundant bacterial phyla and/or classes, such as the prevalence of the Alphaproteobacteria in the culturable sponge fraction and the shift between Flavobacteriia and Sphingobacteriia as the prevalent Bacteroidetes class in seawater and sponge samples, respectively (Figure 5).

Canonical correspondence analysis (CCA) of the whole OTU data revealed that, collectively, independent variables (i.e., seawater, processing methods, and sponge species) could explain
$46.8 \%$ of the total data set variation. The discrepancies between (i) cultivation-dependent and cultivation-independent methods, and (ii) sponge (all handling methods included) and seawater samples accounted for 41.8 and $41.4 \%$ of the explained variability, respectively (Figure S4, Supplementary Material). These values were considerably larger than the individual effects of the sponge species (I. variabilis vs. S. spinosulus, 12\%) and cultivation-independent procedures ("direct" vs. "indirect," 4.8\%) on community data variation. The resulting CCA diagram distinguished seawater, sponges processed with cultivation-independent methods, and sponges processed with the cultivation-dependent method into three sample clusters (Figure S4A). Patterns of host species-specificity became evident when only $I$. variabilis and S. spinosulus specimens characterized by cultivation-independent methods were contrasted (Figure S4B), revealing that each sponge species held its own unique bacterial community. Finally, the shape of $I$. variabilis communities was significantly influenced by the cultivation-independent methods used (Figure S4C), however no such clustering was observed for S. spinosulus (Figure S4D).

\section{IN TUBE FISH-CLSM}

The bacterial groups targeted by FISH were chosen to represent distinct patterns of abundance within the sequencing data set. Whereas Proteobacteria can be regarded as a "generalist" phylum dominant in seawater and sponge communities (both cultured and uncultured), Acidobacteria constitutes a "specialist" phylum with greater abundance within the unculturable sponge microbiome. The detected bacterial cells were mainly cocci found in between sponge cells, with no evidence for a taxon-dependent aggregation of bacteria within the sponge body. In all analyzed samples, bacterial cells were seldom found on spongin filaments. The high abundance of cells precluded discrete counting of cell numbers, and taxon abundance data relative to total bacterial coverage was



FIGURE 5 | Principal coordinates analysis of bacterial community profiles at the phylotype (OTUs) level. Analyses including sponge and seawater samples (A) and sponge samples only (B) are shown, and were performed with normalized sequencing depths [1236 seqs/sample in (A) and 3668 seqs/sample in (B)] using the Unifrac metric. The ten most dominant bacterial taxa (at the phylum or class level) are plotted on both diagrams. Symbol sizes of bacterial taxa correspond to their respective, mean relative abundances across the whole data set. The position of bacterial taxa in the ordination space is determined by the correlation
B



between their relative abundances and the sample categories defined in this study. Colored circles represent replicates within each sample category. Labeling of sample categories is as described in legend to Figure 4, except for both sponge species under the "plate washing" method, which are colored in red. Alternatively, constrained canonical ordination was performed using normalization of abundance data (and not of library size) to determine whether sample categories significantly influence variation in $16 \mathrm{~S}$ rRNA gene profiling by 454-pyrosequencing. These analyses are shown as Supplementary Material (Figure S4). 
retrieved instead. The relative abundance of Alphaproteobacteria in both sponge species was similar: $27.14 \%$ in S. spinosulus (Figures 6A,E) and $22.85 \%$ in I. variabilis (Figures 6B,F), whereas the Gammaproteobacteria were more abundant in S. spinosulus (21.41\%, Figures 6C,E) than in I. variabilis (9.55\%, Figures 6D,F). Both Alphaproteobacteria and Gammaproteobacteria were more abundant than Acidobacteria in S. spinosulus (9.09\%, Figure 6G). In I. variabilis, the abundance of Acidobacteria $(6.20 \%$, Figure $6 \mathbf{H})$ was similar to that of Gammaproteobacteria and lower than that of Alphaproteobacteria. Instead, Acidobacteria 16S rRNA gene tags accounted for 16.91 and $20.68 \%$ of the total communities in S. spinosulus and I. variabilis, respectively, surpassing numbers obtained for Alpha- (3.90\% for S. spinosulus and $4.27 \%$ for I. variabilis) and Gammaproteobacteria (S. spinosulus $9.78 \%$ and $I$. variabilis $11.57 \%$ ) in both sponge species according with 454-pyrosequencing.

\section{DISCUSSION}

\section{SAMPLE HANDLING EFFECTS ON SPONGE BACTERIAL COMMUNITIES} DEPEND ON THE HOST SPECIES

The extent to which existing methods of sample preservation, processing and DNA extraction may affect the structure of sponge symbiont communities is currently under-appreciated. Indeed, detailed analyses comparing sponge microbial community data retrieved with different methodologies are very scarce (see e.g., Hardoim et al., 2009; Simister et al., 2011). The "direct" processing method has been widely used to evaluate the diversity of microbial communities in marine sponges (Hentschel et al., 2002; Taylor et al., 2005; Lee et al., 2011; Hardoim et al., 2012) and is, moreover, the fundamental technique used in metatranscriptomic studies (Radax etal., 2012). By contrast, the "indirect" processing method, through which most of the sponge cells are eliminated, is used in metagenomic, metaproteomic,

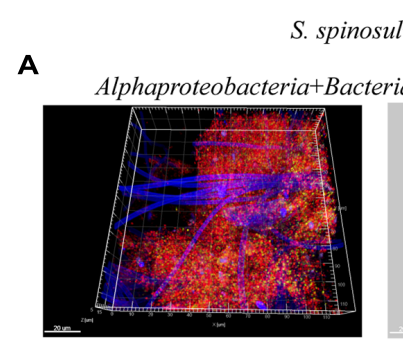

C



E



$\mathbf{G}$

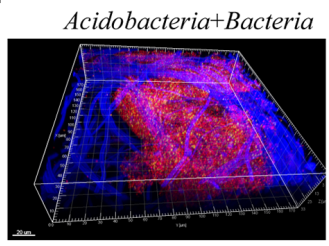

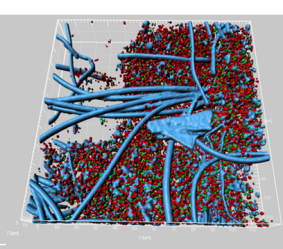



maproteobacteria+Bacteria
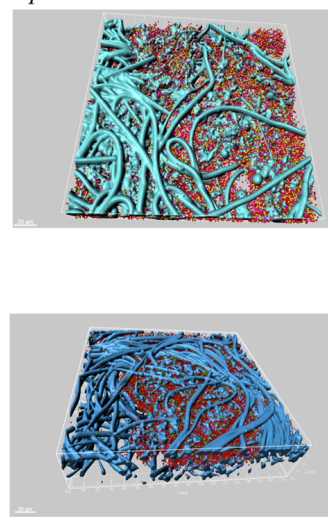

FIGURE 6 | Confocal laser scanning microscopy images of fluorescent in situ hybridization-stained bacteria in $\boldsymbol{S}$. spinosulus and $\boldsymbol{I}$. variabilis. Volume rendering images (left in each panel) and their corresponding 3D reconstructions (right in each panel) are shown for hybridizations with the Cy3-labeled universal bacterial probe (red cells) coupled to ALEXA488- or Cy5-labeled group-specific probes targeting the Alpha- and

Gammaproteobacteria classes and the phylum Acidobacteria. When solely used in combination with the universal probe $(\mathbf{A}-\mathbf{D}, \mathbf{G}, \mathbf{H})$, cells of these
B

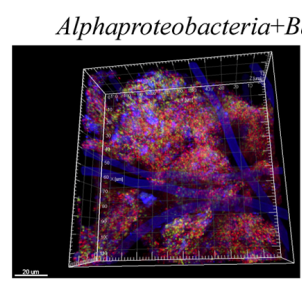

I. variabilis

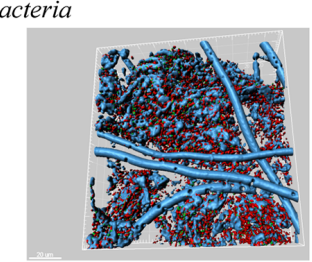

D

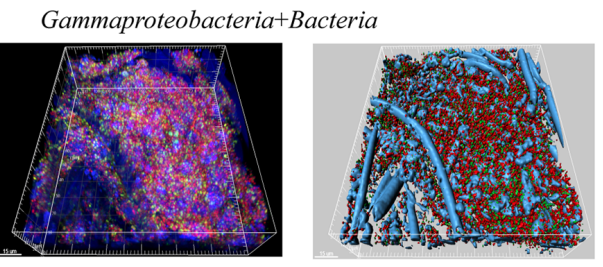

$\mathbf{F}$



H

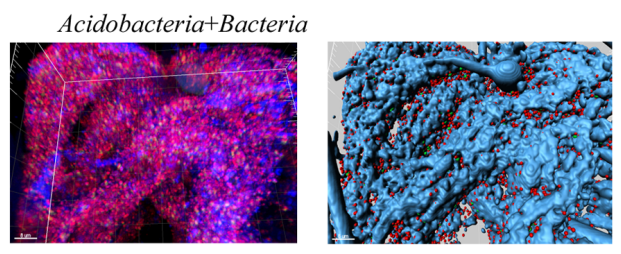

taxonomic groups appear as yellowish cells in the volume rendering images and as green objects in the 3D reconstructions. For co-hybridizations including bacterial, alpha and gammaproteobacterial probes (E,F), the latter two groups are represented by yellowish and pink cells, respectively, except in the 3D reconstruction of $I$. variabilis $(\mathbf{F})$, in which gammaproteobacterial cells appear in purple. Sponge background structure, vastly dominated by profuse spongin filaments, is shown overall in cyan or blue, except in (F) where it is displayed in semi-transparent brown. 
and single cell genomic surveys that target the sponge microbiota (Fieseler et al., 2006; Siegl and Hentschel, 2010; Thomas etal., 2010a; Siegl etal., 2011; Fan etal., 2012; Liu etal., 2012; Bayer etal., 2013). In the present study, both approaches led to similar bacterial diversity and composition results for $S$. spinosulus, but not for I. variabilis. In fact, we found that several OTUs consistently lost abundance while one OTU classified as Acidobacteria showed increased abundance in I. variabilis replicates processed with the "indirect" as compared to the "direct" method (see Appendix S6 for details), resulting in higher methodologically dependent symbiont community variability in this species than in S. spinosulus. This contrast may relate to the density of the collagenous filaments present in the mesohyl of these sponges, which is higher in I. variabilis making this species exceptionally tough and more difficult to tear or cut in comparison with other species in the Irciniidae family (Cook and Bergquist, 2002). Consequently, variability in the mechanical easy of bacterial cell detachment and disruption from the I. variabilis endosome matrix may have resulted in methodology-dependent, non-corresponding community structures retrieved from the same host. Rapid fingerprinting of sponge microbial communities by traditional methods such as PCR-DGGE or T-RFLP may still be an adequate means of assessing whether microbial cell enrichments usually prepared for metagenomics are representative of the community directly determined from the sponge body. Overall, the ability of each cultivation-independent processing method to accurately estimate the actual in situ sponge bacterial community may differ from species to species; therefore preliminary data acquisition to aid in the choice of methodology is advisable prior to in-depth analyses of sponge microbiome diversity and function.

\section{CONTRIBUTION OF ABUNDANT AND RARE OTUS TO HOST-SPECIFIC BACTERIAL COMMUNITY PROFILES}

The degree of conservation of bacterial communities in marine sponges across host species, habitats and oceans has important implications for the management of marine genetic and metabolic resources given the status of these holobionts as the most prolific source of biologically active compounds in the oceans (Piel, 2004). Recent studies have suggested that these communities are host species-specific (Webster et al., 2010; Lee et al., 2011; Schmitt et al., 2012), contrary, in principle, to earlier studies which indicated microbiome conservation across sponge hosts and geographical locations (Hentschel et al., 2002). Through a detailed analysis of sympatric and co-familial sponges this study supports the increasing evidence for host-dependent symbiont community structures among phylogenetically related sponge species, acquired recently with the use of more traditional techniques (Erwin et al., 2012; Hardoim et al., 2012). Qualitatively, the pool of OTUs found exclusively in each species was largely circumscribed by "rare" symbionts: when OTUs deemed as less dominant were discarded from the analysis, the number of "host species-specific" bacterial phylotypes was drastically reduced whereas a strong signal for conservation of the more prevalent symbionts remained. We therefore propose that the views of host-conserved and host-specific bacterial communities in marine sponges are not mutually exclusive, but rather complementary facets of one single biological process. Indeed, the quantitative contribution of the so-called "rare" and often "speciesspecific" OTUs to the total bacteriome of the surveyed sponges was small (c. $1.9 \%$ of all analyzed sequence reads) despite their diversity. Host specificity was therefore found to be chiefly determined by full quantitative profiles including all community members, their corresponding abundance ranks and differences in abundance between host species. Interestingly, the phylumlevel taxonomic composition of the uncultivated, "rare" sponge symbionts resembled that of the dominant symbionts. This could suggest maintenance of core, functional attributes across phylogenetically related microbes with varying abundances within the community, a mechanism that could confer functional stability to the marine sponge holobiont in face of changing conditions, be they host-induced or not. However, closely related bacterial species, and even strains within species, may also have widely differing functions that can result from the acquisition of traits via horizontal gene transfer, a well-documented phenomenon within the Proteobacteria (Costa et al., 2009; van Elsas et al., 2011). In light of the current evidence for abundant horizontal gene transfer potential (Thomas et al., 2010a) and whole genome differentiation among close bacterial relatives within the marine sponge microbiome (Esteves etal., 2013), the net contribution of intra- and inter-species bacterial diversity to the spectrum of functions in these communities remains to be understood.

\section{CULTURABLE SYMBIONTS ESCAPE THE MOLECULAR RADAR}

It has been demonstrated that cultivation-independent methods often fail to detect bacteria isolated with culture-dependent procedures, raising concerns about the validity of cultivationindependent studies (Donachie et al., 2007). In our assay, cultivation of sponge-associated bacteria detected about 35-40 bacterial OTUs per species in comparison with 180-220 OTUs identified by cultivation-independent methods (see Table 3 for details). These ratios surpass typical cultivability estimates based on $\mathrm{CFU} /$ microscopy cell count ratios, which in the case of our sponge specimens was in the range of $0.01-0.1 \%$ (Hardoim et al., 2012). However, about half of the OTUs recovered with the "plate washing" method escaped detection via cultivationindependent approaches, while the remainder was usually detected by the latter procedures in much lower numbers. These results indicate that marine agar culturing enriches for lower abundance symbionts that remain elusive to cultivation-independent methods. Because our methodology enabled direct comparisons between cultured and uncultured microbiomes through a standardized metagenomic DNA analysis pipeline, biases induced by DNA extraction, PCR amplification and colony picking-and-purification procedures are less likely to explain the abrupt differences observed between these communities in our survey. The hypothesis that the cultivatable sponge-associated bacteriome encompasses less abundant phylotypes that are considerably enriched during cultivation, by likely outcompeting more prevalent but less competent and/or slow-growing bacteria, must be assessed with protocols designed to detect rarer populations in the sponge community (Montalvo et al., 2014). 
In this regard, the in-tube FISH-CLSM approach used here to image highly ranked bacterial taxa may be a powerful tool to localize specific and less abundant symbionts in keratose sponges. In this study, FISH-CLSM and 454-pyrosequencing estimates of bacterial abundance were not always congruent. Variable target specificity and coverage between the techniques may have accounted for these differences, although the additional steps required for 454-pyrosequencing (cell detachment and lysis, DNA extraction and PCR) are expected to add more analytical biases compared to the direct FISH-CLSM method. Copy numbers are unlikely to explain the observed discrepancies. Alphaproteobacteria (more abundant in FISH-CLSM than in 454-pyrosequencing results) have an average of 2.4 copies of the ribosomal operon, whereas Acidobacteria (more abundant in 454pyrosequencing) have an average of only 1.6 copies (Klappenbach et al., 2001). These results highlight the importance to use multiple methods for a more comprehensive analysis of symbiont abundance in marine sponges, as proposed elsewhere for other dense microbial settings such as soils (Ushio et al., 2014). Coupling nucleic acid sequencing (especially primer-less approaches, e.g., direct metagenome sequencing) and advanced imaging technologies seems an adequate strategy to be used in upcoming studies.

Although we did not anticipate the detection of Acidobacteria, Chloroflexi, and Poribacteria on culture plates, recent research supports their aerobic and heterotrophic growth capacities (Davis et al., 2011; Siegl et al., 2011; Kamke et al., 2013; see Appendix S7 - Supplementary Material - for a Discussion on Poribacteria results). Due to the very low number of sequences recovered, marine agar showed to be inappropriate for the future isolation of these organisms. Intriguingly, these and other lineages, such as Kiloniella sp. and Ferrimonas sp., could not be detected by a colony picking-and-isolation effort previously applied to our samples (Esteves et al., 2013). Beyond the comprehensiveness of the "plate washing-deep sequencing" procedure used here to characterize the cultivation-dependent communities, this outcome could be explained by the further possibility, enabled by this procedure, of uncovering strictly syntrophic microorganisms or micro-colonies that elude detection by the naked eye (Davis et al., 2011). Finally, the direct comparison between cultivationdependent and -independent communities made in this study shows that traditional cultivation fails at capturing the prevalent bacterial associates of marine sponges. In this context, not only alternative medium recipes and incubation strategies are needed to enhance the cultivability of sponge symbionts in the laboratory, but improvements to our current methods to sample and analyze cultivated sponge microbiomes are desirable to extend our ability to assess the diversity and metabolic capacities of these and other symbiont cohorts in the future.

\section{AUTHOR CONTRIBUTIONS}

Cristiane C. P. Hardoim, Ana I. S. Esteves, and Rodrigo Costa conceived and designed the study. Cristiane C. P. Hardoim, Ana I. S. Esteves, Massimiliano Cardinale, and Rodrigo Costa performed the laboratory experiments. Cristiane C. P. Hardoim, Ana C. B. Cúcio, Massimiliano Cardinale, Cymon J. Cox, and Rodrigo Costa analyzed the data. Rodrigo Costa, Gabriele Berg,
Joana R. Xavier, and Cymon J. Cox contributed reagents, materials and analysis tools. Cristiane C. P. Hardoim, Massimiliano Cardinale, and Rodrigo Costa wrote the manuscript draft. All authors revised the draft, approved the final manuscript version and are accountable for all aspects of the work.

\section{ACKNOWLEDGMENTS}

This work was financed by the Portuguese Foundation for Science and Technology (FCT) through the research project PTDC/MAR/101431/2008 granted to Rodrigo Costa. Cristiane C. P. Hardoim was the recipient of a $\mathrm{PhD}$ fellowship granted by FCT (Grant No. SFRH/BD/60873/2009). Joana R. Xavier research was funded by a FCT postdoctoral fellowship (grant no. SFRH/BPD/62946/2009). Further financial support was obtained from the European Regional Development Fund (ERDF) through the COMPETE (Operational Competitiveness) Programme, from national funds through FCT under the project "PEst-C/MAR/LA0015/2011," and from the FCT-funded research project PTDC/BIA-MIC/3865/2012 granted to Rodrigo Costa.

\section{SUPPLEMENTARY MATERIAL}

The Supplementary Material for this article can be found online at: http://www.frontiersin.org/journal/10.3389/fmicb.2014.00611/ abstract

\section{REFERENCES}

Amann, R. I., Binder, B. J., Olson, R. J., Chisholm, S. W., Devereux, R., and Stahl, D. A. (1990). Combination of 16S rRNA-targeted oligonucleotide probes with flow cytometry for analyzing mixed microbial populations. Appl. Environ. Microbiol. 56, 1919-1925.

Amann, R. I., Ludwig, W., and Schleifer, K. H. (1995). Phylogenetic identification and in-situ detection of individual microbial-cells without cultivation. Microbiol. Rev. 59, 143-169.

Bayer, K., Scheuermayer, M., Fieseler, L., and Hentschel, U. (2013). Genomic mining for novel FADH2-dependent halogenases in marine sponge-associated microbial consortia. Mar. Biotechnol. 15, 63-72. doi: 10.1007/s10126-012-9455-2

Caporaso, J. G., Kuczynski, J., Stombaugh, J., Bittinger, K., Bushman, F. D., Costello, E. K., etal. (2010). QIIME allows analysis of high-throughput community sequencing data. Nat. Methods 7, 335-336. doi: 10.1038/nmeth.f.303

Cardinale, M., Vieira De Castro, J. Jr., Müller, H., Berg, G., and Grube, M. (2008). In situ analysis of the bacterial community associated with the reindeer lichen Cladonia arbuscula reveals predominance of Alphaproteobacteria. FEMS Microbiol. Ecol. 66, 63-71. doi: 10.1111/j.1574-6941.2008.00546.x

Cook, S. C., and Bergquist, P. R. (2002). "Family Irciniidae Gray, 1867”, in System Porifera: A Guide to the Classification of Sponges, eds J. N. A. Hooper and R. W. M. van Soest (New York: Kluwer Academic/Plenum Publishers), 1022-1027. doi: 10.1007/978-1-4615-0747-5_99

Costa, R., Salles, J. F., Berg, G., and Smalla, K. (2006). Cultivation-independent analysis of Pseudomonas species in soil and in the rhizosphere of fieldgrown Verticillium dahliae host plants. Environ. Microbiol. 8, 2136-2149. doi: 10.1111/j.1462-2920.2006.01096.x

Costa, R., van Aarle, I. M., Mendes, R., and van Elsas, J. D. (2009). Genomics of pyrrolnitrin biosynthetic loci: evidence for conservation and whole-operon mobility within Gram-negative bacteria. Environ. Microbiol. 11, 159-175. doi: 10.1111/j.1462-2920.2008.01750.x

Daims, H., Bruhl, A., Amann, R., Schleifer, K. H., and Wagner, M. (1999). The domain-specific probe EUB338 is insufficient for the detection of all Bacteria: development and evaluation of a more comprehensive probe set. Syst. Appl. Microbiol. 22, 434-444. doi: 10.1016/S0723-2020(99)80053-8

Davis, K. E. R., Sangwan, P., and Janssen, P. H. (2011). Acidobacteria, Rubrobacteridae and Chloroflexi are abundant among very slow-growing and mini-colony-forming soil bacteria. Environ. Microbiol. 13, 798-805. doi: 10.1111/j.1462-2920.2010.02384.x 
Donachie, S. P., Foster, J. S., and Brown, M. V. (2007). Culture clash: challenging the dogma of microbial diversity - Commentaries. ISME J. 1, 97-99. doi: 10.1038/ismej.2007.22

Erwin, P. M., López-Legentil, S., González-Pech, R., and Turon, X. (2012). A specific mix of generalists: bacterial symbionts in Mediterranean Ircinia spp. FEMS Microbiol. Ecol. 79, 619-637. doi: 10.1111/j.1574-6941.2011.01243.x

Esteves, A. I. S., Hardoim, C. C. P., Xavier, J. R., Gonçalves, J. M. S., and Costa, R. (2013). Molecular richness and biotechnological potential of bacteria cultured from Irciniidae sponges in the north-east Atlantic. FEMS Microbiol. Ecol. 85, 519-536. doi: 10.1111/1574-6941.12140

Fan, L., Reynolds, D., Liu, M., Stark, M., Kjelleberg, S., Webster, N. S., et al. (2012). Functional equivalence and evolutionary convergence in complex communities of microbial sponge symbionts. Proc. Natl. Acad. Sci. U.S.A. 109, E1878-E1887. doi: 10.1073/pnas.1203287109

Fieseler, L., Quaiser, A., Schleper, C., and Hentschel, U. (2006). Analysis of the first genome fragment from the marine sponge-associated, novel candidate phylum Poribacteria by environmental genomics. Environ. Microbiol. 8, 612-624. doi 10.1111/j.1462-2920.2005.00937.x

Friedrich, A. B., Fischer, I., Proksch, P., Hacker, J., and Hentschel, U. (2001) Temporal variation of the microbial community associated with the Mediterranean sponge Aplysina aerophoba. FEMS Microbiol. Ecol. 38, 105-113. doi: 10.1111/j.1574-6941.2001.tb00888.x

Gomes, N. C. M., Cleary, D. F. R., Pinto, F. N., Egas, C., Almeida, A., Cunha, A., et al. (2010). Taking root: enduring effect of rhizosphere bacterial colonization in mangroves. PLoS ONE 5:e14065. doi: 10.1371/journal.pone.0014065

Hardoim, C. C. P., Costa, R., Araújo, F. V., Hajdu, E., Peixoto, R., Lins, U., et al. (2009). Diversity of bacteria in the marine sponge Aplysina fulva in brazilian coastal waters. Appl. Environ. Microbiol. 75, 3331-3343. doi: 10.1128/AEM.02 101-08

Hardoim, C. C. P., Cox, C. J., Peixoto, R. S., Rosado, A. S., Costa, R., and van Elsas, J. D. (2013). Diversity of the candidate phylum Poribacteria in the marine sponge Aplysina fulva. Braz. J. Microbiol. 44, 329-334. doi: 10.1590/S1517-83822013000100048

Hardoim, C. C. P., Esteves, A. I. S., Pires, F. R., Gonçalves, J. M. S., Cox, C. J., Xavier, J. R., et al. (2012). Phylogenetically and spatially close marine sponges harbour divergent bacterial communities. PLOS ONE 7:e53029. doi: 10.1371/journal.pone.0053029

Hentschel, U., Hopke, J., Horn, M., Friedrich, A. B., Wagner, M., Hacker, J., et al. (2002). Molecular evidence for a uniform microbial community in sponges from different oceans. Appl. Environ. Microbiol. 68, 4431-4440. doi: 10.1128/AEM.68.9.4431-4440.2002

Hentschel, U., Piel, J., Degnan, S. M., and Taylor, M. W. (2012). Genomic insights into the marine sponge microbiome. Nat. Rev. Microbiol. 10, 641-675. doi: 10.1038 /nrmicro2839

Heuer, H., Krsek, M., Baker, P., Smalla, K., and Wellington, E. M. H. (1997). Analysis of actinomycete communities by specific amplification of genes encoding $16 \mathrm{~S}$ rRNA and gel-electrophoretic separation in denaturing gradients. Appl. Environ. Microbiol. 63, 3233-3241.

Hochmuth, T., and Piel, J. (2009). Polyketide synthases of bacterial symbionts in sponges - evolution-based applications in natural products research. Phytochemistry 70, 1841-1849. doi: 10.1016/j.phytochem.2009.04.010

Kamke, J., Sczyrba, A., Ivanova, N., Schwientek, P., Rinke, C., Mavromatis, K. et al. (2013). Single-cell genomics reveals complex carbohydrate degradation patterns in poribacterial symbionts of marine sponges. ISME J. 7, 2287-2300. doi: 10.1038/ismej.2013.111

Klappenbach, J., Saxman, P., Cole, J., and Schmidt, T. (2001). rrndb: the ribosomal RNA operon copy number database. Nucleic Acids Res. 29, 181-184. doi: $10.1093 /$ nar/29.1.181

Kogure, K., Simidu, U., and Taga, N. (1979). Tentative direct microscopy method for couting living marine-Bacteria. Can. J. Microbiol. 25, 415-420. doi: 10.1139/m 79-063

Lee, O. O., Wang, Y., Yang, J. K., Lafi, F. F., Al-Suwailem, A., and Qian, P. Y. (2011). Pyrosequencing reveals highly diverse and species-specific microbial communities in sponges from the Red Sea. ISME J. 5, 650-664. doi: 10.1038/ismej.2010.165

Li, C. Q., Liu, W. C., Zhu, P., Yang, J. L., and Cheng, K. D. (2011). Phylogenetic diversity of Bacteria associated with the marine sponge Gelliodes carnosa collected from the Hainan Island coastal waters of the South China Sea. Microb. Ecol. 62, 800-812. doi: 10.1007/s00248-011-9896-6
Liu, M., Fan, L., Zhong, L., Kjelleberg, S., and Thomas, T. (2012). Metaproteogenomic analysis of a community of sponge symbionts. ISME J. 6, 1515-1525. doi: 10.1038/ismej.2012.1

Manz, W., Amann, R., Ludwig, W., Wagner, M., and Schleifer, K. H. (1992) Phylogenetic oligodeoxynucleotide probes for the major subclasses of Proteobacteria - problems and solutions. Syst. Appl. Microbiol. 15, 593-600. doi: 10.1016/S0723-2020(11)80121-9

Meisinger, D. B., Zimmermann, J., Ludwig, W., Schleifer, K. H., Wanner, G., Schmid, M., et al. (2007). In situ detection of novel Acidobacteria in microbial mats from a chemolithoautotrophically based cave ecosystem (Lower Kane Cave, WY, USA). Environ. Microbiol. 9, 1523-1534. doi: 10.1111/j.1462-2920.2007.0 1271.x

Montalvo, N. F., Davis, J., Vicente, J., Pittiglio, R., Ravel, J., and Hill, R. T. (2014). Integration of culture-based and molecular analysis of a complex sponge-associated bacterial community. PLoS ONE 9:e90517. doi: 10.1371/journal.pone.00 90517

Muscholl-Silberhorn, A., Thiel, V., and Imhoff, J. F. (2008). Abundance and bioactivity of cultured sponge-associated bacteria from the Mediterranean sea. Microb. Ecol. 55, 94-106. doi: 10.1007/s00248-007-9255-9

Neef, A. (1997). Anwendung der in situ Einzelzell-Identifizierung von Bakterien zur Populationsanalyse in komplexen mikrobiellen Biozönosen. Technische Universität München, München.

Piel, J. (2004). Metabolites from symbiotic bacteria. Nat. Prod. Rep. 21, 519-538. doi: $10.1039 / \mathrm{b} 310175 \mathrm{~b}$

Piel, J., Hui, D. Q., Wen, G. P., Butzke, D., Platzer, M., Fusetani, N., et al. (2004). Antitumor polyketide biosynthesis by an uncultivated bacterial symbiont of the marine sponge Theonella swinhoei. Proc. Natl. Acad. Sci. U.S.A. 101, 16222-16227. doi: 10.1073/pnas.0405976101

Quince, C., Lanzen, A., Davenport, R. J., and Turnbaugh, P. J. (2011). Removing noise from pyrosequenced amplicons. BMC Bioinformatics 12:38. doi: 10.1186/1471-2105-12-38

R Development Core Team. (2012) R: A Language and Environment for Statistical Computing. R Foundation for Statistical Computing, Vienna. Available at: http://www.R-project.org

Radax, R., Rattei, T., Lanzen, A., Bayer, C., Rapp, H. T., Urich, T., et al. (2012). Metatranscriptomics of the marine sponge Geodia barretti: tackling phylogeny and function of its microbial community. Environ. Microbiol. 14, 1308-1324. doi: 10.1111/j.1462-2920.2012.02714.x

Schmitt, S., Tsai, P., Bell, J., Fromont, J., Ilan, M., Lindquist, N., et al. (2012). Assessing the complex sponge microbiota: core, variable and species-specific bacterial communities in marine sponges. ISME J. 6, 564-576. doi: 10.1038/ismej.201 1.116

Siegl, A., and Hentschel, U. (2010). PKS and NRPS gene clusters from microbial symbiont cells of marine sponges by whole genome amplification. Environ. Microbiol. Rep. 2, 507-513. doi: 10.1111/j.1758-2229.2009.00057.x

Siegl, A., Kamke, J., Hochmuth, T., Piel, J., Richter, M., Liang, C. G., et al. (2011). Single-cell genomics reveals the lifestyle of Poribacteria, a candidate phylum symbiotically associated with marine sponges. ISME J. 5, 61-70. doi: 10.1038/ismej.2010.95

Simister, R. L., Deines, P., Botte, E. S., Webster, N. S., and Taylor, M. W. (2012). Sponge-specific clusters revisited: a comprehensive phylogeny of sponge-associated microorganisms. Environ. Microbiol. 14, 517-524. doi: 10.1111/j.1462-2920.2011.02664.x

Simister, R. L., Schmitt, S., and Taylor, M. W. (2011). Evaluating methods for the preservation and extraction of DNA and RNA for analysis of microbial communities in marine sponges. J. Exp. Mar. Biol. Ecol. 397, 38-43. doi: 10.1016/j.jembe.2010.11.004

Sipkema, D., Schippers, K., Maalcke, W. J., Yang, Y., Salim, S., and Blanch, H. W. (2011). Multiple approaches to enhance the cultivability of Bacteria associated with the marine sponge Haliclona (gellius) sp. Appl. Environ. Microbiol. 77, 2130 2140. doi: 10.1128/AEM.01203-10

Sogin, M. L., Morrison, H. G., Huber, J. A., Mark Welch, D., Huse, S. M., Neal, P. R., et al. (2006). Microbial diversity in the deep sea and the underexplored "rare biosphere." Proc. Natl. Acad. Sci. U.S.A. 103, 12115-12120. doi: 10.1073 /pnas.0605127103

Staley, J. T., and Konopka, A. (1985). Measurement of in situ activities of nonphotosynthetic microorganisms in aquatic and terrestrial habitats. Ann. Rev. Microbiol. 39, 321-346. doi: 10.1146/annurev.mi.39.100185.001541 
Taylor, J., Schenk, I., Blankenberg, D., and Nekrutenko, A. (2007a). Using galaxy to perform large-scale interactive data analysis. Curr. Protoc. Bioinformatics. Chap. 10; Unit 10.5. doi: 10.1002/0471250953.bi1005s19

Taylor, M. W., Radax, R., Steger, D., and Wagner, M. (2007b). Sponge-associated microorganisms: evolution, ecology, and biotechnological potential. Microbiol. Mol. Biol. Rev. 71, 295-347. doi: 10.1128/MMBR.00040-06

Taylor, M. W., Schupp, P. J., de Nys, R., Kjelleberg, S., and Steinberg, P. D. (2005). Biogeography of bacteria associated with the marine sponge Cymbastela concentrica. Environ. Microbiol. 7, 419-433. doi: 10.1111/j.1462-2920.2004.00711.x

Thomas, T., Rusch, D., Demaere, M. Z., Yung, P. Y., Lewis, M., Halpern, A., et al. (2010a). Functional genomic signatures of sponge bacteria reveal unique and shared features of symbiosis. ISME J. 4, 1557-1567. doi: 10.1038/ismej.2010.74

Thomas, T. R. A., Kavlekar, D. P., and Lokabharathi, P. A. (2010b). Marine drugs from sponge-microbe association - a review. Mar. Drugs 8, 1417-1468. doi 10.3390/md8041417

Ushio, M., Makoto, K., Klaminder, J., Takasu, H., and Nakano, S.-I. (2014). High-throughput sequencing shows inconsistent results with a microscope-based analysis of the soil prokaryotic community. Soil Biol. Biochem. 76, 53-56. doi: 10.1016/j.soilbio.2014.05.010

van Elsas, J. D., Semenov, A. V., Costa, R., and Trevors, J. T. (2011). Survival of Escherichia coli in the environment: fundamental and public health aspects. ISME J. 5, 173-183. doi: 10.1038/ismej.2010.80

Wallner, G., Amann, R., and Beisker, W. (1993). Optimizing fluorescent in situ hybridization with ribosomal-RNA-targeted oligonucleotide probes for flow cytometric identification of microorganisms. Cytometry 14, 136-143. doi: 10.1002/cyto.990140205

Webster, N. S., and Hill, R. T. (2001). The culturable microbial community of the Great Barrier Reef sponge Rhopaloeides odorabile is dominated by an alphaProteobacterium. Mar. Biol. 138, 843-851. doi: 10.1007/s002270000503
Webster, N. S., and Taylor, M. W. (2012). Marine sponges and their microbial symbionts: love and other relationships. Environ. Microbiol. 14, 335-346. doi: 10.1111/j.1462-2920.2011.02460.x

Webster, N. S., Taylor, M. W., Behnam, F., Lucker, S., Rattei, T., Whalan, S., et al. (2010). Deep sequencing reveals exceptional diversity and modes of transmission for bacterial sponge symbionts. Environ. Microbiol. 12, 2070-2082. doi: 10.1111/j.1462-2920.2009.02065.x

Weisburg, W. G., Barns, S. M., Pelletier, D. A., and Lane, D. J. (1991). 16S ribosomal DNA amplification for phylogenetic study. J. Bacteriol. 173, 697-703.

Conflict of Interest Statement: The authors declare that the research was conducted in the absence of any commercial or financial relationships that could be construed as a potential conflict of interest.

Received: 06 September 2014; accepted: 27 October 2014; published online: 18 November 2014.

Citation: Hardoim CCP, Cardinale M, Cúcio ACB, Esteves AIS, Berg G, Xavier JR, Cox $C J$ and Costa R (2014) Effects of sample handling and cultivation bias on the specificity of bacterial communities in keratose marine sponges. Front. Microbiol. 5:611. doi: 10.3389/fmicb.2014.00611

This article was submitted to Aquatic Microbiology, a section of the journal Frontiers in Microbiology.

Copyright (c) 2014 Hardoim, Cardinale, Cúcio, Esteves, Berg, Xavier, Cox and Costa. This is an open-access article distributed under the terms of the Creative Commons Attribution License (CC BY). The use, distribution or reproduction in other forums is permitted, provided the original author(s) or licensor are credited and that the original publication in this journal is cited, in accordance with accepted academic practice. No use, distribution or reproduction is permitted which does not comply with these terms. 